\title{
FREQUENCY OF PULMONARY TUBERCULOSIS ON HIGH RESOLUTION COMPUTED TOMOGRAPHY IN CLINICALLY SUSPECTED PATIENTS VISITING RADIOLOGY DEPARTMENT MAYO HOSPITAL, LAHORE.
}

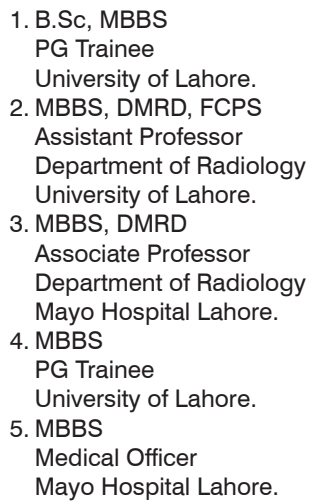

Correspondence Address: Dr. Muhammad Usman Shahid University of Lahore. usmanshahid@gmail.com

Article received on: 29/11/2018

Accepted for publication: 25/03/2019

Received after proof reading: 00/00/2019

\begin{abstract}
Usman Shahid', Faiza Farooq ${ }^{2}$, Khawaja Khursheed ${ }^{3}$, Ishfaq Ahmad Shad ${ }^{4}$, Hira Babar ${ }^{5}$
ABSTRACT... High resolution computed tomography scan, in modern years, is more effective than standard computed tomography scan and conventional chest radiography in localization of diseases in the lobule of lung and in the appraisal of pulmonary parenchymal diseases because of high-resolution power and minimal partial volume effect. Objectives: To identify pulmonary tuberculosis in clinically suspected patients by high resolution computed tomography scan of chest. Study Design: Cross Sectional Descriptive study. Setting: Department of Radiology, Mayo Hospital, Lahore. Period: $15^{\text {th }}$ February 2018 to $15^{\text {th }}$ November 2018. Material \& Methods: After taking consent, fifty patients, fulfilling inclusion and exclusion criteria, were selected by convenient sampling in this cross sectional descriptive study. Demographic details, clinical history and High resolution tomographic scan findings were documented. Data analysis was performed on Microsoft excel and statistical package for social sciences (SPSS v21) and reported by descriptive statistics. Results: Out of 50 patients, pulmonary tuberculosis was diagnosed in $44(88 \%)$ patients, acute on chronic tuberculosis in $2(4 \%)$, healed tuberculosis in $2(4 \%)$, interstitial lung disease in $1(2 \%)$ \& post tubercular sequela in $1(2 \%)$ patient. Majority were males $(n=29,58 \%)$ and most patients belonged to fifth decade of life $(n=19,38 \%)$. Overall mean age of patients was $45.14 \pm 12.16$ years and mostly belonged to lower socioeconomic status $(\mathrm{n}=38,76 \%)$. Most common symptom and High resolution computed tomography finding were low grade fever in $45(95 \%)$ \& consolidation in $39(78 \%)$ patients, respectively. Conclusion: High resolution computed tomography scan is valuable in diagnosis of pulmonary tuberculosis \& its related spectrum of diseases in patients having clinical suspicion of pulmonary tuberculosis.
\end{abstract}

Key words: Chest X-Ray, High Resolution Computed Tomography, Pulmonary Tuberculosis.

Article Citation: Shahid S, Farooq F, Khursheed K, Shad IA, Babar H. Frequency of Pulmonary Tuberculosis on high resolution computed tomography in clinically suspected patients visiting Radiology Department Mayo Hospital, Lahore. Professional Med J 2019; 26(12):2058-2063.

DOI: 10.29309/TPMJ/2019.26.12.1749

\section{INTRODUCTION}

Worldwide, every year $9 \times 10^{6}$ fresh cases of pulmonary tuberculosis (PTB) are diagnosed \& 1.7 million patients die due to this deadly disease. ${ }^{1}$ Majority i.e. $98 \%$ of deaths and $95 \%$ of tuberculosis (TB) cases happen in underprivileged regions of world..$^{1,2}$ Incidence and mortality due to tuberculosis in Pakistan is 27,000 and 54,000 patient's annualy. ${ }^{1}$ From Pakistan, there is $61 \%$ of TB patients in eastern Mediterranean region. ${ }^{2}$ Primary tuberculosis presents as consolidation involving any part of lung with predilection for upper \& lower zones \& can be associated with mediastinal lymphadenopathy. Post primary tuberculosis manifestations are cavitary lesions in superior segment of upper lobe \& upper segment of lower lobe. Endobronchial spread, miliary dissemination, pleural effusion \& empyema are common complications. ${ }^{3}$ Without healing, the perseverance of cavitary lesion is infrequent and must be scrutinized in patients with continuing hemoptysis. ${ }^{4}$ Rasmussen aneurysms are the pseudo-aneurysms of the pulmonary artery caused by cavitation. ${ }^{5}$

For diagnosis of active tuberculosis, microbiological detection of Acid-Fast Bacillus (AFB) is the benchmark; the sputum smear sensitivity for AFB is $46-74 \%$, and the sputum culture sensitivity is $2-95 \%$ with pulmonary TB. ${ }^{4-6}$ 
The national data documents a yield of $10-22 \%$ for smear positivity in active pulmonary tuberculosis in adults. ${ }^{5,6}$ In the evaluation of pulmonary TB, Chest $X$ Rays remain the principal imaging practice but its diagnosis is correct in only $34-59 \%$ cases of primary pulmonary TB and post primary pulmonary TB respectively. ${ }^{2}$ HRCT scan offers better view of interstitial element $\&$ is sensitive in the recognition of exudative lesions of minimum intensity, differentiation of primary from post primary TB, in assessing disease activity, correct identification of bronchiectasis and subtle or occult parenchymal disease. ${ }^{6}$ Miliary lung parenchymal involvement, mediastinal lymphadenopathy, tree in bud appearance which is indicative of endobronchial spread, minimal pleural changes \& the complications of post-primary tuberculosis like the cavitary rupture into the pleural space, erosion of vessels, bronchogenic and miliary are also markedly demarcated. ${ }^{7}$

Lee KS et al, predicted tuberculosis in $91 \%$ patients, excluded TB in $76 \%$ patients, and concluded that difference of inactive from active disease can be completed on the basis of CT scan findings. ${ }^{8}$ Alsowey AM et al, studied the practice of multidetector HRCT scan of chest in identifying PTB patients with sputum negative smears and established a connection between their sputum culture results and their computed tomography (CT) features \& determined accurate diagnosis based on CT scan findings. ${ }^{9}$ HRCT scan can be used for diagnosis of patients with suspicion of active pulmonary tuberculosis but with sputum negative cultures \& can also help for selection of patients for bronchoscopy or additional laboratory tests. ${ }^{10}$ Tozkoparan et al, determined positive predictive value, negative predictive value, specificity, sensitivity and diagnostic accuracy of HRCT in detection of negative sputum culture pulmonary tuberculosis to be $92 \%, 83 \%, 88 \%, 88 \%$ and $88 \%$, respectively. ${ }^{11}$ Objective of this study was to determine the frequency of pulmonary tuberculosis in clinically suspected patients on high resolution CT scan to propose a verdict of tuberculosis in patients non-invasively. HRCT scan may possibly be supportive in identification of PTB and may be valuable in calculation of effectiveness of anti-tuberculous management.

\section{MATERIALS AND METHODS}

After approval from institution's ethical committee, this cross sectional descriptive study was performed at radiology department, Mayo hospital, Lahore from $15^{\text {th }}$ February 2018 to $15^{\text {th }}$ November 2018. Adult patients of either gender up to age of sixty years having clinical suspicion of pulmonary tuberculosis were included. Noncooperative, Immune compromised \& patients with history of malignancy were excluded. Valid informed Consent was taken from patients after counselling the patients regarding the procedure \& objective of the study and right of privacy was ensured. 128 slice Hitachi CT scanner was used to acquire serial slices of $1 \mathrm{~mm}$ in width and 10 $\mathrm{mm}$ apart from apex of the lung to base in supine position and slices were reconstructed on a high-resolution bone algorithm. Scanning time was 2 seconds. All the slices were viewed in Mediastinal window, lung window by consultant radiologist. Data including demographic details, clinical signs \& HRCT findings were collected using questionnaires. Data analysis was done on Microsoft excel \& statistical package for social sciences (SPSS version 21) and reported by descriptive statistics.

\section{RESULTS}

Out of all 50 patients with clinical suspicion of pulmonary tuberculosis, there were 29 (58\%) males and 21 (42\%) female patients with mean age of $45.14 \pm 12.16$ years. Pulmonary tuberculosis was diagnosed in $44(88 \%)$ patients. The demographic details of patients, symptoms and distribution of patients according to HRCT scan findings and diagnosis are shown in table 1 , 2 and 3 , respectively.

\section{DISCUSSION}

Pulmonary tuberculosis is anathema plaguing mankind since antiquity. It's deadly \& contagious so to reduce mortality \& its forward transmission, early accurate diagnosis and prompt treatment should be started. High resolution computed tomographic scan of chest was performed on such sampled patients who had suspicion of pulmonary tuberculosis clinically but had routine tests i.e. sputum culture, lab investigations \& chest $X$ rays inconclusive. 


\begin{tabular}{|c|c|c|c|c|}
\hline \multicolumn{3}{|c|}{ Parameters } & \multirow{2}{*}{$\begin{array}{c}\text { Frequency (n) } \\
29\end{array}$} & \multirow{2}{*}{$\begin{array}{c}\text { Percentage (\%) } \\
58.0\end{array}$} \\
\hline \multirow{2}{*}{\multicolumn{2}{|c|}{ Gender }} & \multirow{2}{*}{$\begin{array}{l}\text { Male } \\
\text { Female }\end{array}$} & & \\
\hline & & & 21 & 42.0 \\
\hline \multirow{4}{*}{\multicolumn{2}{|c|}{ Age (years) }} & $20-30$ & 10 & 20.0 \\
\hline & & $31-40$ & 9 & 18.0 \\
\hline & & $41-50$ & 12 & 24.0 \\
\hline & & $51-60$ & 19 & 38.0 \\
\hline \multirow{3}{*}{\multicolumn{2}{|c|}{ Socioeconomic Status }} & \multirow{3}{*}{$\begin{array}{l}\text { Lower class } \\
\text { Lower middle class } \\
\text { Upper Middle class }\end{array}$} & 38 & 76.0 \\
\hline & & & 11 & 22.0 \\
\hline & & & \multirow{2}{*}{$\frac{1}{\text { details of patie }}$} & 2.0 \\
\hline \multicolumn{4}{|c|}{ Table-I. Demographic details of patients } & \\
\hline \multicolumn{2}{|c|}{ Symptoms } & \multicolumn{2}{|c|}{ Frequency (n) } & Percentage (\%) \\
\hline \multirow{2}{*}{\multicolumn{2}{|c|}{$\begin{array}{l}\text { Low grade fever } \\
\text { Weight loss }\end{array}$}} & \multicolumn{2}{|c|}{45} & 90 \\
\hline & & & & 72 \\
\hline Night swea & & & & 68 \\
\hline Decreased & etite & & & 62 \\
\hline Productive & & & & 56 \\
\hline Nonproduc & cough & & & 44 \\
\hline Hemoptysi & & & & 42 \\
\hline History of $A$ & & & & 30 \\
\hline TB contact & ome & & & 16 \\
\hline TB contact & jorkplace & & & 0 \\
\hline & & Table-II. Distri & patients by symp & \\
\hline & Pare & & Frequency $(n)$ & Percentage (\%) \\
\hline & Consolic & & 39 & 78 \\
\hline & Ground & pacity & 38 & 76 \\
\hline & Fibrosis & & 32 & 64 \\
\hline & Cavitatio & & 31 & 62 \\
\hline & Tree in b & searance & 29 & 58 \\
\hline HRCT & Miliary $n$ & & 25 & 50 \\
\hline Findings & Bronchie & & 24 & 48 \\
\hline & Pleural $\mathrm{t}$ & & 21 & 42 \\
\hline & Pleural $\epsilon$ & & 9 & 18 \\
\hline & Mediasti & phadenopathy & 8 & 16 \\
\hline & Pleural c & tion & 2 & 4 \\
\hline & Chest w & Ivement & 0 & 0 \\
\hline & Pulmona & & 44 & 88.0 \\
\hline & Acute or & ic TB & 2 & 4.0 \\
\hline Diagnosis & Healed & & 2 & 4.0 \\
\hline & Post tub & is sequela & 1 & 2.0 \\
\hline & Interstitic & disease & 1 & 2.0 \\
\hline
\end{tabular}

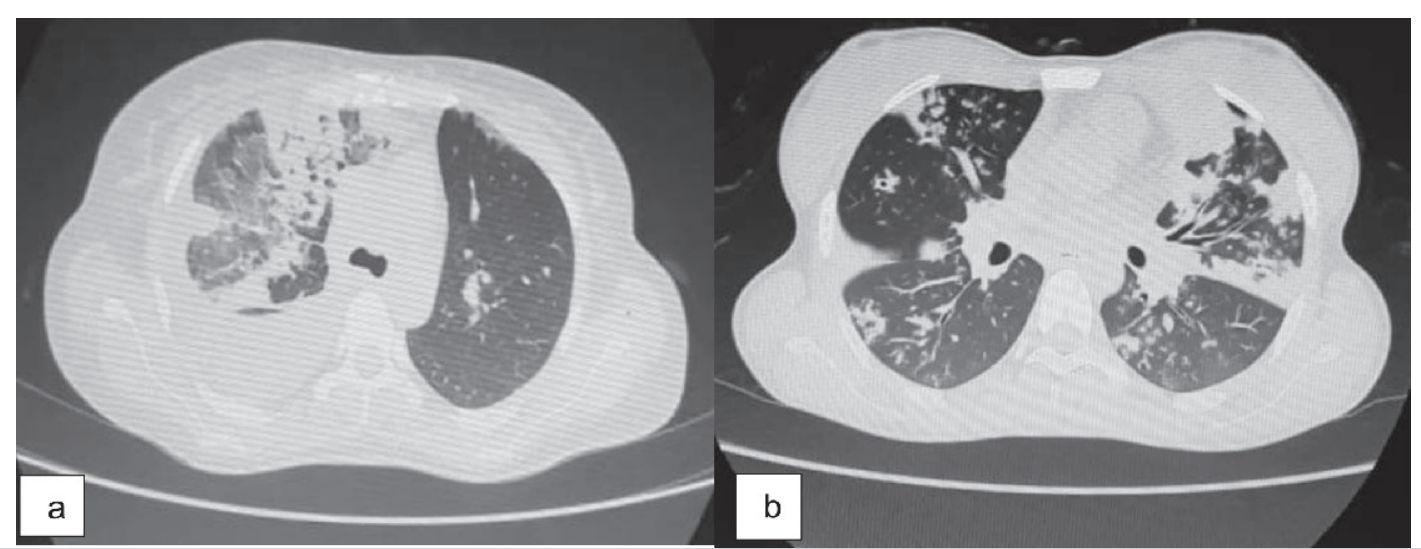

Figure-1. HRCT scan of chest (axial slice of lung window) showing (a) consolidation with air bronchograms involving upper \& middle lobe of right lung and (b) tree in bud appearance in bilateral lung fields 
Current study depicted that pulmonary tuberculosis was diagnosed radio graphically by HRCT scan of chest in 88 percent of patients $(n=44)$ who had suspicion of disease on clinical grounds. It also differentiated patients of acute on chronic tuberculosis $(n=2,4 \%)$, Healed tuberculosis $(n=2,4 \%)$, interstitial lung disease $(n=1,2 \%)$ and with post tubercular sequela $(n=1,2 \%)$. Most of the patients belonged to 51 60 years of age group comprising of $38 \%$ (19) of patients with mean age of $57.26 \pm 3.19$ years.

Overall mean age of patients was $45.14 \pm 12.16$ years in our study. Similarly, in a study by Bakhshayesh KM et al, the mean age of patients was $47.15 \pm 22.6$ years. ${ }^{12}$ In our study, Majority of the patients were males comprising $58.0 \%$ (29) of the cases and $21(42.0 \%)$ were females which is similar to study by Capone RB et al, by whom out of 74 patients with tuberculosis of active nature, $54 \%$ were men \& $46 \%$ were women. ${ }^{13}$ In our study, $76 \%$ (38) of patients belonged to lower socio-economic class and same was found by Oren et al. ${ }^{14}$

In our study, Low grade fever was the most common symptom followed by weight loss in $26(72 \%)$ patients which is supported by study of Capone RB et al who found weight loss in $69 \%$ of patients. ${ }^{13}$ Night sweats were seen in 34 (68\%) patients in our study. It supports findings of study carried out by Bakhshayesh KM et al which concluded night sweats in $62.7 \%$ of patients. ${ }^{12}$ In our study, Hemoptysis was seen in $42 \%$ (21) of patients which is contradictory to findings by Alsowey AM et al who found it in $30 \%$ of patients. ${ }^{9}$ Chief HRCT finding in our study was Consolidation (Figure-1-a) i.e. 78\% (39 patients) and this is similar to results by Rufino RL et al who determined consolidation in $77 \%$ of patients..$^{15}$ In our study, the frequencies of Ground glass opacification, tree in bud appearance (Figure1-b) \& fibrosis were found different than some previous studies. ${ }^{16,17}$ Cavitation, in our study, was seen in $62 \%$ of patients which is similar to 58 $\%$ of patients observed in a study by JG Im et al. ${ }^{18}$ In our study, multiple miliary nodules were seen in $50 \%$ of (25) patients which is supported by findings of study by Pereira I et al. ${ }^{19}$ Alsowey
AM et al found mediastinal lymphadenopathy in $15.33 \%$ of patients which is similar to findings of our study i.e. $16 \% .^{9}$

Known as barometer of social welfare, pulmonary tuberculosis mimics quite number of diseases in terms of clinical and investigative findings so its diagnosis remains elusive. In clinical practice in our country, it is diagnosed on basis of sputum culture, Chest X-rays and laboratory tests but it can be misleading if bacterial load is minimal in sputum, disease is at milder stage or incorrect sampling of saliva of patient instead of sputum is done. Sputum culture is also time consuming and can be false negative. Chest X-ray has poor diagnostic sensitivity \& specificity. Procedures like Broncho alveolar washings have higher diagnostic accuracy but are invasive, expensive, and not readily available in our country and may be intolerable to some patients. HRCT scan is noninvasive in nature, highly effective and sensitive in localization of disease in lobule and airways of lungs due to high-resolution power and has no temporal limitations and can correctly identify primary tuberculosis, post primary tuberculosis, healed tuberculosis as well as endobronchial spread of disease. Although this study presented some limitations like sample size was not much large and noninvolvement of multiple radiologists for diagnosis \& reporting of HRCT scan can lead to bias in results.

\section{CONCLUSIONS}

It is concluded by this study that HRCT scan is valuable in diagnosis of pulmonary tuberculosis \& its related spectrum of diseases in patients having clinical suspicion of pulmonary tuberculosis. It is sensitive in picking of subtle pathological changes and can comment on endobronchial as well as miliary spread of disease. HRCT scan is recommended when routinely adopted diagnostic measures like Chest X-ray and sputum culture yield inconclusive results.

Copyright $\odot 25$ March, 2019.

\section{REFERENCES}

1. World Health Organization. Global tuberculosis report 2018. 
2. Atif M, Anwar Z, Fatima RK, Malik I, Asghar S, Scahill S. Analysis of tuberculosis treatment outcomes among pulmonary tuberculosis patients in Bahawalpur, Pakistan. BMC research notes. 2018; 11(1):370.

3. McAdams HP, Erasmus J, Winter JA. Radiologic manifestations of pulmonary tuberculosis. Radiol Clin North America. 1995; 33(4):655-78.

4. Gadkowski LB, Stout JE. Cavitary pulmonary disease. Clin Microbiol Rev 2008; 21(2):305-33.

5. Seedat UF, Seedat F. Post-primary pulmonary TB haemoptysis-When there is more than meets the eye. Respir Med Case Rep 2018; 25:96-9.

6. Hill LE, Ritchie G, Wightman AJ, Hill AT, Murchison JT. Comparison between conventional interrupted high-resolution CT and volume multidetector CT acquisition in the assessment of bronchiectasis. $\mathrm{Br} \mathrm{J}$ Radiol 2010; 83(985):67-70.

7. Allwood BW, Goldin J, Said-Hartley Q, van ZylSmit RN, Calligaro G, Esmail A, Beyers N, Bateman ED. Assessment of previous tuberculosis status using questionnaires, chest X-rays and computed tomography scans. Int J Tuberc Lung Dis 2015; 19(12):1435-40.

8. Lee KS, Im JG. CT in adults with tuberculosis of the chest: Characteristic findings and role in management. AJR 1995; 164(6):1361-7.

9. Alsowey AM, Amin MI, Said AM. The predictive value of multidetector high resolution computed tomography in evaluation of suspected sputum smear negative active pulmonary tuberculosis in Egyptian Zagazig University Hospital patients. Pol J Radiol 2017; 82:808.

10. Shaarrawy H, Zeidan M, Nasr A, Nouh M. Assessment of the role of high resolution computed tomography in the diagnosis of suspected sputum smear negative active pulmonary TB. Egypt $\mathrm{J}$ Chest Dis Tuberc 2013; 62(2):263-8.

11. Tozkoparan E, Deniz O, Ciftci F, Bozkanat E, Bicak M, Mutlu H, Ors F, Bilgic H, Demirci N. The roles of HRCT and clinical parameters in assessing activity of suspected smear negative pulmonary tuberculosis. ARCH MED RES Journal 2005; 36(2k):166-70.
12. Bakhshayesh $\mathrm{KM}$, Masjedi $\mathrm{M}$, Fadaeizadeh $\mathrm{L}$, Doukouhaki P, Sadeghi S, Alinejad TS, Tabatabaei S. Role of HRCT in diagnosing active pulmonary tuberculosis. Arch Iran Med 2000; 3(1).

13. Capone RB, Capone D, Mafort T, Mogami R, Rodrigues RD, Menna Barreto M, Rufino R. Tomographic aspects of advanced active pulmonary tuberculosis and evaluation of sequelae following treatment. Pulmonary medicine 2017; 2017.

14. Oren E, Narita M, Nolan C, Mayer J. Neighborhood socioeconomic position and tuberculosis transmission: A retrospective cohort study. BMC infectious diseases. 2014; 14(1):227-38.

15. Rufino RL, Capone R, Capone D, Costa $\mathrm{CH}$. Pattern of chest computed tomography before and after treatment in patients with proven pulmonary tuberculosis. InB50. Diagnosis and treatment of active tuberculosis disease 2015 May (pp. A3309-A3309). American Thoracic Society.

16. Hatipoğlu ON, Osma E, Manisali M, Ucan ES, Balci P, Akkoclu A, Akpinar O, Karlikaya C, Yüksel C. High resolution computed tomographic findings in pulmonary tuberculosis. Thorax 1996; 51(4):397-402.

17. Ghosh M, Giri S, Ghosh A, Biswas S, Dan U. Study to evaluate the pattern of involvement by computed tomography in sputam positive pulmonary tuberculosis. IJSR 2018; 7(3):31-3.

18. Im JG, Itoh H, Shim YS, Lee JH, Ahn J, Han MC, Noma S. Pulmonary tuberculosis: CT findings early active disease and sequential change with antituberculous therapy. Radiol 1993;186(3):653-60

19. Pereira M, Gazzoni FF, Marchiori E, Irion K, Moreira J, Giacomelli IL, Pasqualotto A, Hochhegger B. Highresolution CT findings of pulmonary Mycobacterium tuberculosis infection in renal transplant recipients. Br J Radiol 2015; 89 (1058):20150686. 


\begin{tabular}{|c|c|c|c|}
\hline \multicolumn{4}{|c|}{ AUTHORSHIP AND CONTRIBUTION DECLARATION } \\
\hline Sr. \# & Author(s) Full Name & Contribution to the paper & Author(s) Signature \\
\hline 1 & Faiza Farooq & $\begin{array}{l}\text { Literature review, Compilation, } \\
\text { Data analysis, Manuscript } \\
\text { writing, Correspondence. } \\
\text { Data review and proof reading. }\end{array}$ & \\
\hline 3 & Khawaja Khursheed & Data review and interpretation. & \\
\hline 4 & Ishfaq Ahmad Shad & Data collection. & alkeg \\
\hline 5 & Hira Babar & Data collection. & \\
\hline
\end{tabular}

